\title{
“Why should a 'foreigner' be better than me?": preferential practices in junior academic faculty recruitment among mainland Chinese universities
}

\author{
Ningyang Chen ${ }^{1}$
}

Received: 10 September 2020 / Accepted: 27 October 2021 / Published online: 28 November 2021

(c) The European Higher Education Society 2021

\begin{abstract}
China's phenomenal growth in higher education has received increasing scholarly attention, particularly its initiative to build world-class universities. Though a crucial contributor to its rapid development, the changing hiring practices of mainland Chinese university employers remain largely underexposed. This study presents qualitative evidence drawn from document analysis and in-depth interviews to show current trends, which reveal university employers' widespread preference for graduates with an overseas background, will tend to deprive domestically trained graduates of vital opportunities for career development, which may have detrimental consequences in the long run. The study found that a substantial number of Chinese university employers explicitly articulated their talent preferences, with a strong favour towards applicants with overseas credentials and/or experience. Further analysis of the textual data identified two nuanced trends: universities in a more economically developed region and at a higher level tended to have more rigid and exclusive recruitment preferences for candidates with an overseas background; competitive employers tended to be selective in applicants' overseas backgrounds by gauging their potential productivity measured in quantifiable research outputs. In response to the pressure brought by such preferential practices, domestic doctorates were found to be learning to accept and struggle to cope with the changes. These findings are discussed in the context of the internationalisation of higher education and the popularisation of overseas education with implications for and beyond the Chinese experience.
\end{abstract}

Keywords Overseas returnees · Preferential hiring · Junior academic faculty $\cdot$ Faculty recruitment . The internationalisation of higher education · Overseas education

Ningyang Chen

rosaliechen@126.com

1 School of Foreign Languages, Soochow University, No. 1 Shizi Street, Suzhou, Jiangsu, People's Republic of China 


\section{Introduction}

In today's higher education, ambitious universities tend to be overachievers when it comes to human resources management, as building quality faculty is key to the success of the business of universities. While a relatively comprehensive picture has been drawn of the world's established systems (e.g., Burgan, 2006; Clark \& Ma 2005; Crothall et al., 1997; Hearn et al., 2013; Marini, 2018), the faculty management practices of universities in higher education systems that are undergoing rapid changes have been studied to a lesser extent (Jung, 2018). As a high-achieving rising system, China's higher education has received growing scholarly attention (Song, 2018), with its talent management policy being one of the prominent topics of discussion. Research has been focusing on the country's talent strategies to reverse its brain drain and policies to recruit overseas returnees to empower its higher education (Cao, 2008; Ha et al., 2016; Marini \& Yang, 2021; Mok \& Han, 2016; Tharenou \& Seet, 2014; Zweig, 2006). Moreover, studies have been conducted to examine the adaptation experiences of overseas returnees and how these experiences may impact on their academic career development (Jiang et al., 2020; Li et al., 2015; Li et al., 2019; Li \& Xue 2021).

As the country's economy continues to cruise along, a growing number of Chinese families have been able to afford and would willingly invest in their children's international learning experience. With an estimated 545,000 students studying abroad in 2016, China has become the world's largest exporter of international students (Ministry of Education, 2018). In the same year of 2016, an estimated 433,000 foreign-educated graduates returned to China to work, making a high returnee rate of $82.23 \%$ (ibid.). On the other hand, growing at an equally rapid pace is the country's domestic postgraduate education enterprise (Yang, 2012; Zheng et al., 2018). In the 13th Five-Year Plan period (20162020), the pre-set goal of having "two postgraduate students in one thousand people" was achieved ahead of schedule, reaching an estimated total of three million students studying in various postgraduate programmes in the year 2020 (Ministry of Education "China has established the world's largest higher education system", 2020). During the five-year period from 2016 to 2020, 330,000 doctoral degrees and 3.39 million master's degrees were awarded (ibid.). Given the scale of these two streams of talents, competition in the domestic job market is intense. Though both foreign-educated and home-grown graduates face challenges in landing a desired job, the pressure and specific concerns for each differ across fields of expertise, institutional backgrounds, and levels of academic training.

The current study focuses on the competition between foreign-educated and homegrown Chinese $\mathrm{PhD}$ students who aspire to pursue an academic career by seeking junior academic positions in domestic higher education institutions (HEIs). Previous studies have shown that the former hold a distinct advantage in the domestic job market, because the high-skilled returnees are equipped with a range of new knowledge, skills, attitudes, and perspectives in virtue of their international learning experience (Hao \& Welch, 2012). Zweig et al. (2004) calculated a significantly higher value of a foreign $\mathrm{PhD}$ versus a domestic $\mathrm{PhD}$, with returnees employed by domestic universities faring better in all measured aspects, including promotion, mobility, human capital, funding, and importing foreign technology and information. Comparable findings were obtained in $\mathrm{Li}$ and $\mathrm{Pu}$ (2017), who reported a unanimous positive perception of returnee recruits among 20 Chinese university presidents, who spoke highly of the overseas-trained academics' research performances compared with their home-grown colleagues. 
Judging from the doctoral self-reports and the employer feedbacks, it seems evident that the returnee candidates would be favoured in the academic labour market due to their competitive edge. Yet, to what extent such a preference is expressed and practised by the prospective employers remains largely unknown. Meanwhile, considering the changes in domestic and international doctoral education over time, some of the observations drawn from earlier data are to be updated. For instance, a secondary finding in Zweig et al. (2004, p. 143) that foreign PhDs were significantly older than domestic PhDs may no longer be considered representative of the two groups of doctoral graduates two decades later. With China becoming a more experienced exporter of international students, Chinese students who plan to study abroad have been better informed to prepare for a smoother experience than their predecessors. Meanwhile, their domestically trained peers may have to spend longer time in the programme for reasons such as unemployability and institutional barriers against graduation (Wang et al., 2019), hence a reduced age disparity. This and related emerging trends warrant further research on how the hypothesised competition scenario plays out in the real world.

The current study intends to explore this topic from dual perspectives of the university employer and the PhD student, focusing on the manifestation of employers' preferences and domestic PhD students' attitudes and responses. The employer perspective was investigated by a textual analysis of academic faculty recruitment advertising documents publicised by 36 universities at different geographical locations and under different levels of supervision. This dataset was supplemented by informants' views collected from administrative staff members. The student perspective drew from in-depth interviews with nine domestic $\mathrm{PhD}$ students and three foreign $\mathrm{PhD}$ students. The rest of the paper proceeds as follows. It first offers a brief overview of faculty recruitment in the Chinese higher education system. Afterwards, it explains the design and procedure of the study. The study findings are then reported and illustrated with excerpts of the qualitative data. This is followed by a further discussion of the results and the implications for research and practice. The paper closes with conclusive remarks and possible lines of future work.

\section{Faculty recruitment in the Chinese higher education system}

Historically and to varying extents today, education and other public service sectors in China have been in close connection with the government by their performative role as "shìyè dānwèi." Its English equivalence has been variously rendered as "public service units" or "government agencies and public institutions" (Wong, 2009). According to the official definition and classification, it is an umbrella term for three types of "gōngyi" ("non-profit") institutions at three distinctive levels (State Council, 2011). Those in sectors that serve the fundamental public good (or the most "basic" public service), such as public healthcare and compulsory education, are labelled as Category I, suggesting the highest degree of a direct governance relationship and budgetary support. On the opposite side, Category III institutions belong to sectors that operate on market-oriented principles with self-generated profits, as in mass media services of TV broadcasting and newspaper publishing. In between these two categories is Category II, into which the higher education sector falls (ibid.). As Category II public service units, Chinese HEIs are granted a degree of autonomy and implemented control. Hence, HEIs can have their say in some decision-making circumstances concerning the competitive market-based allocation of 
resources rather than succumbing completely to centralised planning (ibid.). This unique "in-between" positioning in the country's sociopolitical system adds layers of complexity to the operation of Chinese HEIs, as the flexibility granted to an individual institution may vary based on the tie it maintains with the supervisory body.

Despite its indefinite degree, such flexibility was indicative of the significant progress of China's higher education, as it departed from the era of the planned economy when universities had little autonomy over their hiring practices, strictly following a "directionbased" centralised model (Qin, 2007, p. 89). It was a time when graduates would be allocated to work where they were deemed most needed. The university reform during the 1950s for social construction reinforced faculty allocation by "a national assignment system" (Gaskell et al., 2004, p. 513). A typical Chinese phrase for this type of employment is "bāo fēnpèi" ("secured assignment"); thus, one who was assigned a teaching position in a university would be admired for securing an "Iron Rice Bowl" job (Fan et al., 2017, p. 41). With the country's opening up and economic reform, the academic staffing practice in China has undergone dramatic changes, gradually moving away from the allocation model to an increasingly marketised, competitive "two-way choice" hiring system (Gasket et al., 2004, p. 515).

Alongside the changing patterns of university faculty recruitment, the perceived idea of a "dàxué lăosh $\vec{\imath}$ " ("university teacher") has been changing in the professional and public discourse. The "university teacher" as a profession was historically situated when highskilled intellectual labour was scarce nationwide and junior academic faculty was mainly made up of selected graduates (often undergraduates) who "liúxiào rènjiào" ("stayed in school to teach"). Academic titles and mobility remained largely foreign to the public, as the university teacher was thought of as belonging to the generic profession of teaching in state-regulated institutions, where one would turn teaching apprenticeship at his/her alma mater into a career-long commitment. Such has been the early yet influential recruitment practice in the Chinese higher education system before it embarked on internationalisation. The practice rested on a model centring around the notion of "biānzh" ("establishment of posts", Brødsgaard, 2002), which is characterised by security and immobility with a full array of benefits in housing, promotion, and many others associated with stable employment. Into the era of reform and growth, the Westernized system of higher learning began to establish itself in internationalising institutions around the country, bringing in notions such as "academic," "professorship," and "mobility," and the localisation of these notions has helped update the public understanding of the profession. Nonetheless, the lasting influence of the long-established recruitment model continues to be felt. A recent topic of keen debate has been the cancellation of "biānzhi" across the country's HEIs. Though hardly unpredictable, this unsettling news has aroused anxiety among university faculty members and doctoral students who plan to work in the university. While some took it as evidence for deepening marketisation, others interpreted it as a sign for greater autonomy of Chinese HEIs in human resources management.

One overall trend can be detected in the changing design and circulation of the university's recruitment notices. For example, Xiong (2012) analysed 48 advertisements for academic posts published in an official Chinese newspaper and summarised the major rhetorical strategies used to establish the institution's credentials, introduce its incentives, programmes and facilities, promote its brand, and consolidate the bureaucratic discourse - all could be taken as evidence for increasing marketisation of higher education. As Chinese HEIs gain greater control over their hiring practices, several diverse forms of recruitment notices have emerged over the years, a tendency facilitated by the internet and advancing technology. Nowadays, university employers would often issue their school-based 
recruitment plans and year-round recruiting notices on the university website and social media sites, e.g., broadcasting the content of the notices via WeChat articles. A typical opening of the public recruitment notice, which is often entitled "réncái zhāopìn jihuă" ("talent recruitment plan"), would read as follows:

Following State Regulations on the Public Recruitment Practice of Faculty Members by Public Service Units, to meet its needs for growth, University X plans to publicly recruit teaching faculty in YY (year of the scheduled recruitment).

Written in the form of a public notice, the body of the notice often includes a brief description of the institution, basic requirements, hiring process, and contact information. The basic requirements listed in the notice often cover nationality (e.g., Chinese citizenship), ethics (e.g., "abide by laws and regulations, devote oneself to the national education course, display an enterprising drive to work hard, and a strong sense of responsibility and dedication") and physical fitness. Accompanying the notice text would often be a document titled "University X's YY open recruitment plan for academic positions," which encompasses a full list of the available positions with (or sometimes without) specific descriptions of position-based requirements. It should be noted that the Chinese-language advertising document mainly targets Chinese applicants. Advertisements tailored for international applicants would adopt a different format and wording that resemble the job posts in the international academic labour market. They often include more details on job descriptions and responsibilities and focus on candidates' overall abilities and experiences.

To sum up, the faculty recruitment practices in the Chinese higher education system cannot be adequately understood without taking into account the historical context and refraining from imposing the interpretative model based on established systems. Shaped by its origin, tradition, and socio-cultural embedding, the changes in recruitment patterns can be more complex than a shift from "being assigned as a university teacher" to "landing an academic job." More subtle changes as to how university employers would compete verbally for high-skilled talents remain to be explored. The current study thus focused specifically on employers' selection of junior academic faculty among two groups of talents - those who have been cultivated in domestic programmes and those who have received overseas training. In a real-life scenario, the study asked: When the university employer considers a domestic academic job candidate who has just finished his/her academic apprenticeship, how important is the candidate's overseas experience? Two specific questions were proposed to guide the inquiry:

1. How important is one's overseas experience, as expressed in the domestic advertising documents of academic faculty recruitment?

2. What are domestic doctoral students' attitudes and responses to the challenge of competing with their foreign-educated peers?

\section{Methods}

The purpose of the study was two-fold: to find out whether and to what extent an overseas background preference existed in academic hiring among Chinese university employers and to investigate how domestic PhD students responded to this situation. A qualitative design was adopted to explore the research questions. Recruitment advertising documents 
from 36 HEIs in mainland China and interviews with $12 \mathrm{PhD}$ student informants and three administrative staff members constituted the data source of the study.

\section{Data collection}

A sample of 36 baccalaureate degree-granting institutions was randomly selected from the list of officially accredited HEIs (Ministry of Education, 2015), where each institution was sorted by its geographical location (e.g., in a specific city or municipality directly under the central government) and supervisory body (e.g., a government department or a municipality). For a balanced sample, care was taken to ensure that an equal number of HEIs were included to represent each of the three geographical locations: eastern coastal, central interior, and western (Liu, 2015) and the three levels of supervision: a government department (e.g., Ministry of Education), a provincial government (e.g., Jiangsu Province), and Department of Education at the provincial level (e.g., Jiangsu Provincial Department of Education). The latter categorisation of the selected HEIs was in rough accord with the ranking based on the institution's performance and prestige; hence three distinctive tiers could be specified, with higher-level supervision over higher-tier institutions. As the university-wide talent recruitment plan was not guaranteed to be released on a regular yearly basis (it was not uncommon to find a oneor two-year gap between releases of such recruitment documents by some institutions), the most recently publicised public recruitment notice was taken from the website of the human resources (HR) department of each target institution. The websites were visited from January to October 2018, and the collected documents were publicised from 2017 to 2018. The document sets examined in the study included the public notice and the attached position description file (if there was one available).

To guide the interpretation of the advertising texts and investigate how domestic $\mathrm{PhD}$ students responded to the recruiting policies and practices, in-depth interviews were conducted with 12 informants opportunistically sampled from three national key universities in three eastern coastal cities in China. Admittedly, a balanced sample of informants would need to include doctorate-granting institutions in other parts of the country and less prestigious institutions. Due to the limited scale of the study, however, only the opinions from the informants that were approachable by the researcher were obtained. These informants included one HR department staff member and three doctoral students at each university. All the domestic $\mathrm{PhD}$ student informants (S1-S9) received academic training (including pre-admission educational experience of bachelor's and master's studies) in mainland Chinese institutions. They had, on average, spent less than six months abroad (Table 1). For a comparative interest, three foreign-trained $\mathrm{PhD}$ student informants were included. One (S10) had obtained his bachelor's and master's degrees from University A before going to a prestigious university in the Netherlands for a doctoral degree. One (S11) had obtained her bachelor's degree from one of China's top universities before getting admitted to a master's programme run by an elite university in the United Kingdom. After earning her master's degree, she went on to complete a $\mathrm{PhD}$ at the same university. Another (S12) had also obtained his bachelor's degree from University A and was then selected into a joint doctoral programme that allowed him to conduct his research in an elite university in the United Kingdom. These three informants were approached because they had comparable academic experiences with several domestic PhD student informants before gaining their international learning experience. For instance, S1 and S10 were in the bachelor's and the master's programmes (both in 


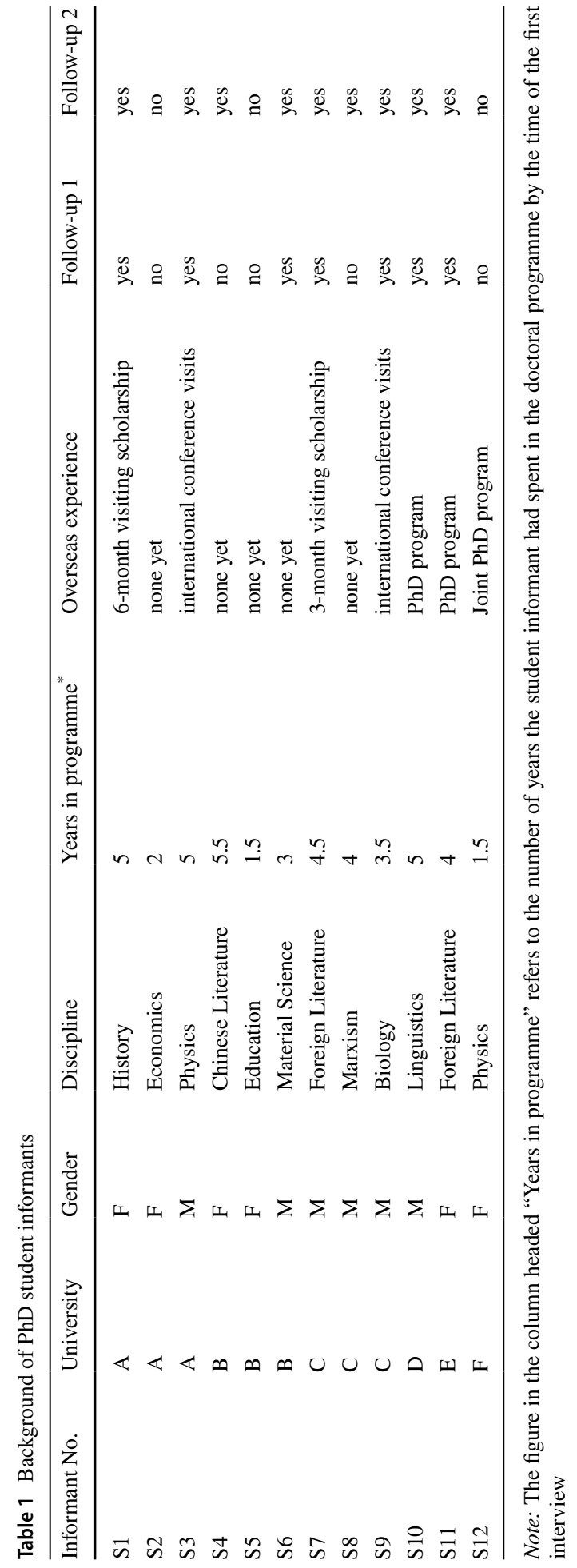


the humanities departments) in the same university at roughly the same time. Regarding educational background, the only difference seemed to be that $\mathrm{S} 1$ received her doctoral training in a domestic institution whilst S10 received a foreign $\mathrm{PhD}$. Some (e.g., S4, S7 and S11, S3 and S12) were in similar domains of study, yet they received different training at the postgraduate level. Thus, they formed interesting pairs for comparison.

The semi-structured interviews focused on the informants' career plans and perceptions of overseas experience. They were also queried about their interpretations of representative text excerpts and were invited to comment on the preliminary textual findings. Five of the domestic PhD student informants (S1, S3, S6, S7, S9) and two of the foreign PhD student informants (S10 and S11) obtained their degrees before 2019 and another two (S4 and S8) from 2019 to 2021. With these nine students, follow-up interviews were carried out to track their job-hunting and employment experience. The first round of interviews with all the informants was conducted from September 2018 to March 2019. The follow-up interviews were conducted with the graduated student informants from July to December 2019 (follow-up 1) and from May to July 2021 (follow-up 2). The informants' insights and perspectives helped guide the analysis of the textual data and domestic doctorates' perceptions of and responses to the situation.

\section{Data analysis}

Each public recruitment document was scrutinised for descriptions of overseas credentials. These included statements mentioning overseas academic degrees, research and/or teaching experience gained abroad. The search was manually conducted and checked using a corpus search tool (Anthony, 2015) to ensure all mentions of overseas credentials were captured. All the concerned instances were then marked and collected to help gauge the salience of overseas credentials mentioned in each document. Then the instances were reread in the context of the full document to determine its expressed or indicated degree of flexibility or rigidness towards overseas credential requirements. The reoccurring phrases were coded and served as model cases for labelling each category (Table 2) and sorting out the related mentions in the documents.

\section{Findings}

Overall, it was found that the recruitment advertising documents varied greatly in their degree of thoroughness and the number of recruiting positions. While the most thorough document spanned over ten pages, a couple of documents gave no further information except the hiring department, position title, and the number of available positions. A general tendency was that the higher-level institutions offered more positions and more detailed descriptions in their advertising documents. Given such apparent differences, it would not be valid to sort the individual institution into a particular category (e.g., an unbiased employer) based merely on the number of specific mentions of position-based requirements in the text, since such a practice would run the risk of biasing against universities with less fully-developed documents. Neither would it be a sound treatment to subject the results to a robust comparison (e.g., it would be difficult to draw a comparison between a brief document with a general statement and an elaborated document with repeated mentions). Therefore, a holistic evaluation was attempted based on the salience of the overseas credential descriptions in each text sample. In general, it was estimated that $63.9 \%(83.3 \%$, $66.7 \%$, and $41.7 \%$ respectively among institutions in the eastern coastal, central interior, 


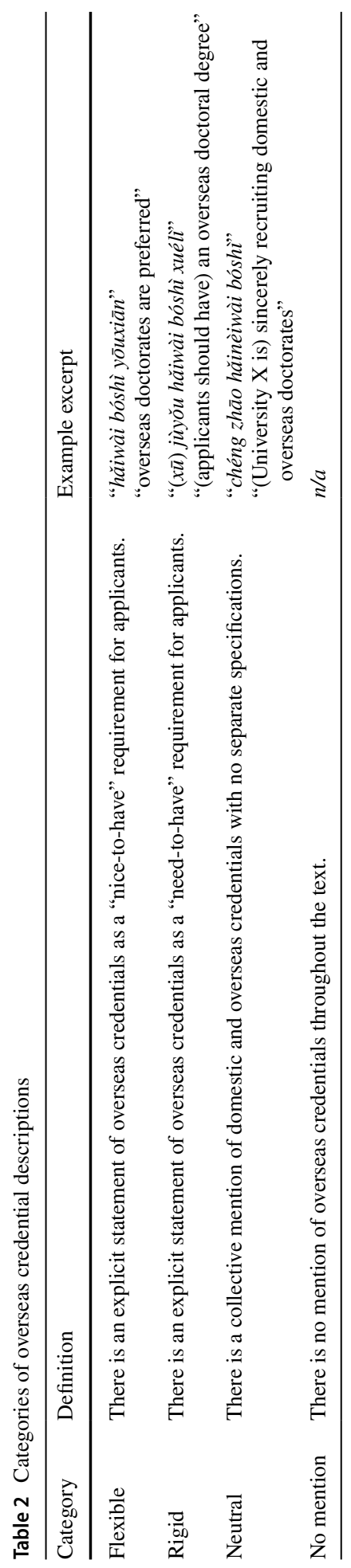


and western regions; $91.7 \%, 75.0 \%$, and $25.0 \%$ respectively among institutions under the governmental, provincial, and departmental level of supervision) of the analysed documents included mentions of requirements concerning an "overseas background," which was typically specified as an overseas academic degree (predominantly at the doctoral level), teaching and/or research experience at an overseas university or a research institute.

Moreover, specific linguistic evidence was dominant that pointed to a preference for foreign $\mathrm{PhDs}$ over domestic PhDs. Revealing evidence can be gleaned from the reference wording in Chinese for the doctoral degree. In a fair number of advertising documents, an overseas background was mentioned as a marked category, with its domestic counterpart being the unmarked default. That is, when unspecified, the Chinese phrase "bóshi xuéli" ("a doctoral degree") was used to refer to one obtained from a domestic university. In contrast, one obtained overseas was specified with a modification: "hăiwài bóshi”" ("an overseas doctorate"). Linguistically, to exclude the overseas sub-category from a generic term for special, emphatic mention can be considered a preferential practice in its own right.

\section{Trends in hiring practices}

Two distinctive trends emerged from the analysis of the textual data. One was that institutions in more economically developed provinces and supervised by a higher-level governing body tended to adopt more rigid and exclusive recruitment preferences for candidates with an overseas background. Though it needed to be statistically testified in future work, the level of the institution appeared to play a more significant role than the geographical location in predicting the degree of rigidity of the preferential practices. The other related trend was the competitive employers' preoccupation with applicants' potential productivity and competitiveness as gauged by institutional ranking and quantifiable research outputs.

\section{From "overseas preferred" to "overseas required"}

One frequently reoccurring set of expressions found in the recruitment advertising documents identified overseas credentials as a "nice-to-have" requirement, e.g., "yǒu hăiwài jiàoyù bèijǐng zhě youxiān" ("candidates with an overseas educational background are preferred"). For example, in the 2018 advertising document of a provincial university in an eastern coastal city, up to $60 \%$ of the recruiting positions considered overseas credentials as the desired requirement (see Excerpt 1). Another second-tier university in an eastern coastal city adopted emphatic wording ("We emphasise..."), indicating the eagerness and sincerity with which it welcomed overseas talents (Excerpt 2).

Excerpt 1

School: School of Architecture and Urban Planning.

Hiring criteria: The applicant shall have graduated from a prestigious university with a doctoral degree and have a clear research direction in the field of architecture; candidates with an overseas educational background will be preferred. ${ }^{1}$

\section{Excerpt 2}

\footnotetext{
1 The interview excerpts throughout the paper were originally in Chinese and were translated to English by the author (to keep the implicature of the original wording intact, the translation was more literal than idiomatic). Expressions concerning an overseas background were italicized for emphasis.
} 
The university is recruiting doctorates and post-doctorates from prestigious universities home and abroad. The applicant shall be below 35 years of age. We emphasise the introduction of talents who have obtained doctoral degrees from well-known overseas universities or those who have over one year of overseas training experience.

Apart from expressions of a clear preference for holders of degrees obtained overseas, there were several cases where a less transparent message was conveyed that academic achievements made in an overseas context mattered more than those achieved in the domestic context. Hence, one's international learning experience could compensate for the lack of credentials in other aspects such as teaching experience or a senior academic title. For instance, one second-tier university in an eastern coastal city described succinctly in the criteria for a prospective faculty member for its School of Business: "(the applicant) shall be a professor or an associate professor with an overseas degree)." A similar equation was drawn between a home-grown $\mathrm{PhD}$ and a foreign-educated master's in the documents of several third-tier universities, e.g., "(the applicant) shall hold a doctoral degree or alternatively, a master's degree obtained overseas." Moreover, documents with similar wording as in the above excerpts often went together with differential compensation policies for the two types of talents. Some of the benefits promised for foreign-trained recruits, compared with those for their domestically trained counterparts included a higher salary, more "kēyán qùdòng jīngfèì" ("research start-up funding"), and often a superior-sounding title, e.g., "hăiwài lǐngjūn réncái” ("leading overseas talent").

Despite the diverse ways in which overseas talents were valued more than their domestic counterparts, the second- and third-tier institutions articulated relatively flexible recruitment policies concerning candidates' overseas experience, which invited domestic graduates to compete, at least as the document presented. This chance was denied, however, in a fair number of recruitment advertising documents published by the first-tier universities, which included positions that stated an overseas background as a basic requirement (see Excerpt 3).

Excerpt 3

School: School of Energy and Power Engineering.

Discipline: Aerospace propulsion theory and engineering.

Position Title: Associate-professor-in-waiting.

Hiring Criteria: The applicant shall have obtained a doctoral degree from a well-known overseas university, or have the experience of working in a well-known overseas university for over two years. The applicant shall not, in principle, be older than 35 years.

This excerpt was taken from the 2018 recruitment notice of a national key university in an eastern coastal Chinese city. Above the age requirement, the university prioritised the degree requirement - that the applicant shall, above all, have an overseas doctoral degree of a decent kind or alternatively working experience in an overseas institution. As the position targeted junior academics (below 35 years of age), and working experience was often premised on an academic apprenticeship, the criterion basically requested a doctoral degree obtained from a prestigious university overseas. The applicant who met these requirements would expect to have a chance to be hired as a "zhǔnpin fùjiàoshòu" ("associate-professor-in-waiting"). Dissimilar to the nontenure track positions in disguise (Roemer $\&$ Schnitz, 1982), this and other popular junior academic positions - another was "shīzi bóhòu" ("post-doctoral teacher") - promised "real" employment if the candidate could satisfy requirements for a qualified employee within the period of the contract (ranging 
from three to six years). As the HR staff member informants revealed, though teaching was often included in the requirements, the meaningful part of the contract primarily centred on research outputs.

In terms of disciplines, the mandatory requirement for an overseas background was not limited to natural sciences. Social sciences and humanities, too, were following suit. This was the case even with faculties that were mainly devoted to the studies of local concerns, as a position posted for the School of Marxism of a first-tier university stated:

Excerpt 4

\section{School: School of Marxism.}

Discipline: Ideological and political theory.

Position Title: Assistant professor.

Hiring Criteria: The applicant shall hold a local hukou, or has obtained an overseas doctoral degree or has finished post-doctoral training in the year of recruitment; the applicant shall be below 35 years of age; the applicant shall be a Chinese Communist Party member.

As the position was specified in the requirements, the candidate was expected to conduct courses for "sīxiăng zhèngzhì lìlùn kè" ("ideological and political education"), which have been widely taught in Chinese universities (Lu, 2017). For one thing, it seemed dubious whether an overseas degree in Marxism or related fields of study would benefit local students' ideological and political education. For another, the practice of giving equal weight to a hukou of a first-tier city ${ }^{2}$ and an overseas degree provided further interesting evidence for the practical "added value" of an international learning experience.

Considering the pressure from high-level supervision and competition, it was unsurprising that China's first-tier university employers had rigid requirements for applicants' overseas credentials, as presented in their recruitment advertising documents. However, two of the top universities in the dataset adopted a non-preferential stance towards applicants' academic credentials, as illustrated in Excerpt 5.

\section{Excerpt 5}

School: School of Mathematics.

Discipline: Mathematical science.

Position Title: Assistant professor/Associate-professor-in-waiting.

Hiring Criteria: The applicant shall be below 35 years of age; the applicant shall have a doctoral degree in foundation mathematics, applied, and computational mathematics, or related fields of study; the applicant shall have experience researching the field s/he is engaged in and have the ability or potential to lead the development of the discipline.

Given this sweeping wording, it was difficult to judge whether the university employer would favour foreign-trained candidates or not. Similar neutral wording was used to refer to the two groups of $\mathrm{PhDs}$, as in "X University welcomes doctorates from home and abroad to join its XX School." To find out whether such linguistic vagueness meant a sincere

\footnotetext{
2 The hukou (household registration) system in China has a direct influence on the resident's access to a range of social benefits including medical services and educational resources. First-tier cities (e.g., Beijing, Shanghai, Guangzhou) set high criteria for local hukou registration that have been raised over time (Zhang et al., 2019).
} 
invitation for domestic PhDs to compete, profiles of the recently recruited (since 2018) academic faculty by the school or department involved in the advertising documents of the two non-preferential-sounding universities were collected from the university websites in June $2021 .^{3}$ The incomplete record ${ }^{4}$ revealed an exclusively overseas background of the recently hired faculty. Further analysis of the new faculty members' overseas experiences pointed to a refined recruitment pattern across disciplines. The pattern suggested that the newly recruited social sciences and humanities faculty had obtained a doctoral degree from an elite overseas university or a joint doctoral programme with an elite overseas university. In addition to an overseas $\mathrm{PhD}$, the majority of the new faculty in natural sciences also had post-doctoral and/or research experience in overseas institutions. One HR staff member informant explained that this "language trick" did not turn the universities into unbiased employers - "the top ones are the most strategic and the most subtle." Yet, when comparing rhetoric with reality, the innocent-sounding expressions may have served to avoid offending sensitive readers and shield the university employer from a possible critique of its hiring preferences.

\section{Distinctive overseas background with potential productivity}

Alongside more rigid and exclusive preferences, a related trend emerged in the recruitment practices among the first-tier university employers. That is, they targeted specifically talents whose quality was controlled and guaranteed by the prestige of their $\mathrm{PhD}$-granting institution and whose potential productivity were confirmed or suggested by their preemployment performance. For instance, in over half of the first-tier university's advertising documents, the applicant was expected to hold a doctoral degree obtained from a "worldclass university," defined most often as "the world's top 100." One university was even considerate enough to attach a QS World University ranking file to its advertisement. Thus, it seemed evident that the academic hiring policy pronounced by these competitive employers was skewed towards candidates from elite universities. This finding was supported by a summary of the educational background information of the faculty recruited from 2018 to 2021 by the aforementioned two top universities in the dataset. Discipline-specific ratings of institutional prestige differed, yet nearly all the recently recruited junior academics whose profiles were accessible were found to hold degrees granted by the world's leading institutions (top 100), with no shortage of graduates from those at the apex, such as Oxford

\footnotetext{
3 The data collection followed a stepwise procedure. First, the advertising documents of the two nonpreferential-sounding universities were reread to generate a list of positions available to junior applicants, specified by an age limit (e.g., below 35 years of age) and/or the position title (e.g., assistant professor, junior researcher). The positions were sorted by the hiring school or department in each university. Then, the website of each school or department involved in the recruitment was visited to find those recently hired for these or possibly other positions released after the 2018 advertisements. As the newly recruited faculty was not specified (often all the faculty members were listed in alphabetical order of the teachers' first names), a search was done manually to check each faculty member's webpage, where the academic's educational background and work experience were introduced briefly with a description of their research interests and achievements. Those whose webpage information indicated a junior academic (judged by the year of graduation) and recent employment (e.g., the description of their work experience included such wording as "joined the School/Department in 2019") were targeted for analysis. For each individual, information was collected on their educational background and pre- and post-employment productivity (e.g., PhD-granting institution, research experience and publications).

4 Due to possible delay in website updating and unfilled positions, less than half of the positions described in the advertising documents were matched with the corresponding hired faculty members.
} 
and Harvard. Due to the limited data and possible bias (e.g., the faculty members with a more "presentable" profile might be more likely to have their information publicised on the university website), the evidence could only be taken as anecdotal.

It was not surprising that the eager employers were liable to fall easy prey to assumptive judgements, hence an expressed preference for the established brands. Such a phenomenon was associated with a "credential privilege" or "pure prestige" effect in the literature. The effects of the university brand have mainly been discussed in the US context (Burris, 2004; Headworth \& Freese, 2016; Oprisko et al., 2013). However, such a "brand effect" may work somewhat differently in the Chinese context. In an established system like the UK and the US, the halo over the old elite institutions had been created by the time-honoured traditions and practices. Thus, the "institutional pedigree" phenomenon in hiring (Oprisko et al., 2013) may be due to efforts to maintain the heritage of elitism. However, in a fastgrowing system like China, the local brands may have only begun to gain international attention despite their domestic acknowledgement and popularity. It was thus understandable that the internationally-minded domestic employers would favour the world's leading players over the local "big names." One HR informant jokingly compared this preference tendency to vehicle brand choices: "It's like Chinese people buying cars. It used to be a choice between Volkswagen and Toyota. You wouldn't even think of Dongfeng or Changcheng. Now more people begin to turn to domestic brands. But of course, education won't grow as fast as the car industry."

With regard to gauging candidates' competence and potential, Jiang et al. (2020) found that pre-employment academic productivity, rather than the prestige of the host university, played a significant role in the job placement of the candidate in a top Chinese university. Thus, it was expected that another trend in the advertising practice would be for the employer to elaborate on the criteria for pre-employment research outputs, a direct measure of academic productivity. Such a practice was found to be expectedly popular among the first-tier demanding employers who bothered to specify their expectations using exceptionally detailed language. For example, the general hiring criteria in Excerpt 3 were followed by a thorough description of the "minimum requirements" stated as follows:

Excerpt 6

The applicant shall meet one of the following minimum requirements:

(a) Over the past five years, the applicant has published no fewer than eight papers in First or Second Quartile (Q1/Q2) SCI(E)-indexed journals as the first author or the corresponding author, or has published, as the first author or the corresponding author, at least one ESI highly cited paper; (b) the applicant has won the first or second prize (ranking top 5) of a national award or has won the first prize (top 3) or second prize (top 2), or third prize (top 1) of a provincial or ministerial science and technology award; and has, over the past five years, published no fewer than five papers in First or Second Quartile (Q1/Q2) SCI(E)-indexed journals as the first author or the corresponding author.

In contrast to the scarce mention of teaching experience in the hiring requirements, the description of the requirements for proven productivity was very detailed. This stark contrast echoed the observation made in Oprisko et al. (2013): "In academic hiring, candidates are often evaluated almost entirely upon their research output rather than their teaching prowess or service." As illustrated in Excerpt 6, the evaluation criteria often included the minimum number of papers published in journals with prestige, as in internationally or domestically recognised indexing sources (e.g., Science Citation Index, Social Sciences 
Citation Index, Chinese Social Sciences Citation Index). Some document compliers even went to greater lengths to specify the authorship and the status of the submission, as showcased below in the publication requirement for an assistant professor position in business administration at a first-tier university.

Excerpt 7

The applicant shall have received minor revisions (English original) for submissions to a journal in the A+ level journal list of the School of Economics and Management; the applicant shall be the first author or the corresponding author of the submission (in cases where the first author is the applicant's doctoral supervisor and the applicant is the second author, the applicant can be considered as the first author).

The above examples showed that the competitive university employers were preoccupied with applicants' pre-employment productivity, which played a crucial role in their hiring decisions. Statistically, it has been proven that Chinese doctoral returnees with more international journal publications had a better chance to get an academic position in the top domestic universities (Jiang et al., 2020).

Though the majority of the first-tier universities had spelt out their requirements for research outputs, some chose to eschew the "distasteful" (Hirsch, 2005, p. 16,569) quantifiable measure. Instead, they adopted rather vague wording such as "the applicant shall have experience researching the field $\mathrm{s} / \mathrm{he}$ is engaged in and have the ability or potential to lead the development of the discipline" (as shown in Excerpt 5 above). Does this mean that these top employers would focus more on the potential than the proven competence of the applicant? The profile analysis results indicated that these employers cared about both the candidate's potential and competence, yet in a more calculating way. According to the information presented on their university webpages, the recently recruited junior faculty in natural sciences mostly had stunning records of publications. In social sciences and humanities, however, some recently hired academics did not have many journal publications during their doctorate (more often, they had rich experience in conference presentations and research internships). Yet, they had a series of publications within a short time after they were recruited. It was common for the recruited academics to publish work from their $\mathrm{PhD}$ project with a dual affiliation (the degree-granting institution and the recently joined institution). As explained by an HR informant, the strategy was to spot those who would have many papers published. Unlike the domestic programmes which had made journal publication mandatory for $\mathrm{PhD}$ students (Wang et al., 2019), the overseas institutions often left it for their students to decide whether or when they would like to publish their research. Hence, in disciplines where research publication took time, it would be strategic to "save" the publication for later. Those who planned to return often would not hasten to submit their manuscripts while they were in the programme but would do it later towards graduation to add their current affiliation in time for the publication to come out. Then, it would win credit for both institutions and promotion at the current institution, a "win-win strategy", as commented by one HR informant.

\section{Domestic students' attitudes and responses to the "overseas" peer pressure}

More striking than the inconsiderate written calls was how the preferential recruitment practices had been passively reacted to among the domestic PhD students. To varying degrees, the interviewed domestic $\mathrm{PhD}$ students wavered between confusion and 
acceptance in response to the university employers' preferential practices. Though some felt offended by the "outspoken words," they generally did not think they had much of an alternative but succumbed to the new academic hiring norms. A sense of helplessness and disorientation dominated the informants' reflections and comments.

\section{Offended and confused}

The five domestic $\mathrm{PhD}$ students who had obtained their degrees before 2019 experienced various challenges in finding an academic job upon graduation. With a six-month visiting scholarship, $\mathrm{S} 1$ had the best international profile among all the domestic $\mathrm{PhD}$ informants. However, she remained jobless for over 12 months after graduating from University A in 2017. As a native to the local community, she did not wish to leave her hometown city to work elsewhere. Therefore, after spending a gap year, she landed a non-academic position in her alma mater. She felt it a pity that she was denied a teaching position despite her presentable publications and visiting scholar experience at a US university. The following excerpt illustrated her disapproval and confusion over the employer's decision.

Excerpt 8

It's beyond my understanding why the university's Department of History would favour overseas returnees over domestic graduates. I mean, can those trained in foreign contexts really do better in studying Chinese history? They may have an advantage in doing studies in global history, but I don't think they can do as well in researching domestic topics. (S1)

The fact that S1 was denied an academic position in her alma mater could be taken as indicative of a sufficient supply of returnee talents, since the country's top universities were the doctoral returnees' first choice for building an academic career back home (Jiang et al., 2020). The appeal of the institutional brand was heightened by the geographical advantage as the country's top performers in higher education gathered mainly in a handful of developed cities. Half of the institutions on the country's 42 world-class university list are located in first-tier cities, with the international cities of Beijing and Shanghai boasting over a quarter of the elite institutions (Ministry of Education "list of world-class universities and first-class disciplines", 2020). With talents of various types and backgrounds being attracted to a tiny number of universities, there was a steady, ample supply (in some popular fields of study, a possible oversupply) of elite returnees, driving the hiring policies to become more selective and exclusive. With some fast-developing institutions, the "overseas returnee only" policy had been practised for years, as one HR informant proudly acclaimed that they had been recruiting only foreign $\mathrm{PhDs}$ since 2009.

Nonetheless, it was confusing why her nice record of publications failed to compensate for S1's lack of an overseas degree - she had published seven articles in prestigious local Chinese-language journals during her postgraduate studies, which was rare in the field. In addition, she had published two translated book chapters of an introduced scholarly work from the US, as she had a good command of English. This confusion was partially resolved when comparing her experience with that of S10, who spent his bachelor's and master's years in the same university at roughly the same time. Graduated from University A's Department of Chinese Language and Literature, S10 went to the Netherlands to continue his research into Chinese dialects. He was first interviewed shortly before he graduated 
from the programme in 2018 when he was making up his mind on whether to return or not. When asked about his career plan, S10 replied:

Excerpt 9

[Compared with domestic PhDs,] I think my CV looks more beautiful (English original), you know, the international publications - I started to publish internationally in English only after I came here. And I think I also have more [job] opportunities. I can stay [in the Netherlands] and continue my research work here - my supervisor has offered to fund my post-doc project. Or, I can go back [to my alma mater] and work there. In fact, they (professors who taught my undergraduate courses) have already contacted me about it - I guess they sort of "want me back." (S10).

Apart from the tendency to tacitly equate "international" scholarly output with English-language publications, there was an undertone of superiority in his remarks as he celebrated the linguistic capital derived from his international learning experience. S10's words were borne out by previous studies (e.g., Li et al., 2019; Jiang et al., 2020) that measured the academics' productivity by counting their international English-language rather than domestic Chinese-language publications due to the better recognition, visibility, and international benchmarking effect of the former (Jiang et al., 2020, p. 540). Thus, trained in a predominantly monolingual context, the domestic PhDs would often find it challenging to publish in English as a foreign language. Among the nine domestic $\mathrm{PhD}$ students interviewed, only the three in natural sciences (S3, S6, and S9) had published their research in English, mainly because it was the common practice in their fields. Yet, they confessed that they were more capable of conducting an experiment than writing about it and thus depended much on their supervisors to revise and submit the paper. Though the correlation between one's overseas learning and development of competence to use English for research publication purposes awaited to be proven, the pressure to produce knowledge via a language that they generally lacked experience with may have weighed the domestic $\mathrm{PhDs}$ down.

\section{Helpless yet accepting}

Though she had to compromise her career aspiration, S1 was the only domestic PhD graduate who landed a job in a first-tier university. The rest of the graduates in the study made early compromises with their goals by lowering their expectations or seeking alternatives. They did so because they had either "grown used to unfair practices" or made themselves believe that "the best solution is to realise the harshness of the reality and to adapt to it."

S7 graduated from University $\mathrm{C}$ in 2018 and landed a job in an average university in a second-tier city where "competition is less fierce" and "a domestic doctoral degree still matters." Before getting this job, she tried yet failed several times to apply for a position in a "better" university in the eastern coastal city where she studied. Although she had spent some research time in a renowned university in the UK as a visiting scholar during her third $\mathrm{PhD}$ year, she explained that short-term visiting scholarships did not count as much in the academic job market, especially when other applicants were all overseas $\mathrm{PhD}$ holders. Nevertheless, when reflecting on her job-hunting 
experience, S7 seemed to have reasoned herself out of the negative feeling of inferiority and frustration:

Excerpt 10

I know there may be a bias of some sort, but I can't do anything about it. So, I'd rather see it as the changing game rule since everything is changing fast in China. You need to find one way or another to adapt to your surroundings, not the other way around - if you don't want to be taken out of the game early. (S7)

Having realised the value of overseas experience in their further career opportunities, the doctoral students interviewed who had not yet had any overseas experience were planning to gain some while still in the programme. However, chances for gaining overseas experience did not come equally, as students in some disciplines tended to have easier access than students in other disciplines. Both S4 (specialising in Chinese literature) and S8 (specialising in Marxism) had zero overseas experience and did not expect to get any. In the first interview when she had spent five and a half years in the programme, S4, who wanted but failed to apply for a visiting fellowship, explained, "Although there are several programmes available, it is more difficult for students in humanities and some social science subjects to get a chance, for the policies are often in favour of natural science students." This observation was extended by the insights shared by the two young scientists (S6 and S9) who both chose to get some "proper" overseas post-doctoral training before settling down with a job. The biology $\mathrm{PhD}$ explained his choice as follows:

Excerpt 11

In my field, if you have no overseas experience, you can't compete with others, and you probably won't be able to land a teaching position in a university... I've had travelled abroad once or twice to attend international conferences, but that won't count. You need time to build connections and network with international researchers. Only then will you get the most "research output" benefit out of your overseas experience. (S9)

The mentioned benefits of gaining post-doctoral research experience abroad were in line with the profile-based finding that the recently recruited faculty in natural sciences mostly had overseas post-doctoral experience. For university employers, apart from the necessary training to sustain research achievement, the integrating effects (Melin, 2004) generated from the post-doctoral experience could also make a difference. In comparison, S12, who was much younger than the two domestic scientists, seemed to have made a wiser and more productive investment by going on a joint doctoral programme. In the most recent interview, S12 shared his growing list of publications in top-level journals, which came out of his active involvement with the leading research team in the host university.

By the end of the three-year study, seven of the nine domestic PhD informants had obtained their degrees. One got a non-academic job in her home university; one was hired by a second-tier university; two went abroad for post-doctoral training; while one (S3) was still waiting for the delayed result of his application for an overseas post-doctoral programme. S4 and S8, who graduated during the COVID-19 pandemic lockdown, had to postpone their job-seeking activities. When interviewed, neither expressed high expectations for an academic job in the university. S4 mentioned that she was preparing to compete against doctoral graduates from "qīnghuá běidà" (Tsinghua University and Peking University) for a teaching position in a local middle school. The two domestic PhD informants (S2 and S5) who remained in the programme were not optimistic about their future. 
Majoring in economics, S2, who came from a family of teachers, sounded particularly pessimistic.

\section{Excerpt 12}

I've already given up pursuing the academic path. Not that I'm not interested, but that the chance for me to get a teaching position in my field - where there is no shortage of overseas talents - is very slim. ... I know my family would be hugely disappointed in me, for they expect me to be a university teacher. I don't know what the future holds whether I could find a job or what kind of job would be available. Currently, my biggest concern is whether I can graduate or not. (S2)

Regrettable as her situation was, this "quitting attitude" was somewhat predictable from previous survey results. A recent one reported that about one-third of academic PhDs trained in domestic programmes got non-academic jobs, including a considerable proportion of top-quality $\mathrm{PhDs}$ (Bao et al., 2020) and over half expected a non-academic profession (Gu et al., 2018). On the face of it, this seemed to mean the expansion of opportunities and diversification of choices, thus adjusting the goal of domestic doctoral training accordingly to prepare students for non-academic jobs sounded like a reasonable suggestion (Gu et al., 2018). Nonetheless, we may wonder how many would still choose to spend years in a gruelling, specified training programme knowing that they would end up as a "versatile expert" (ibid.).

\section{Discussion}

The qualitative findings above suggest two topics worthy of further discussion. One arises from the revealed preferential recruitment policies and practices as targeted by the first research question; the other accounts for the pressure experienced by the domestic PhDs as assessed in the second question. The discussion, though drawing from evidence from the Chinese context, may have significant relevance to rising systems that are confronting the emerging trends in internationalisation and massification of higher education and offer meaningful implications for research and practice.

\section{"Outsourced" talent training as a fast lane towards internationalisation}

Given the pressure to advance towards internationalisation and world-class distinction, the mainland Chinese university employers' shared preferences for overseas doctorates were more revealing than surprising. Similar (e.g., Jung, 2018) or opposite (e.g., Chiang, 2021) tendencies have been identified in other national and regional contexts. To a large extent, China's stunning progress in internationalising its higher education sector over the recent decade shares the feature in common with its expansion practices that are built on the East Asian model of a "strong nation-state structure with instrumentalism" (Jiang \& Ke, 2021). Commenting on the institutionalisation of internationalisation of higher education in China, Cai (2014) noted:

In general, the internationalization in Chinese higher education is a goal in itself, in spite of a clear policy intention to increase the international competitiveness of Chinese higher education through cooperation with foreign HEIs. Both the Chinese 
government and HEIs are heavily committed to achieving those objectives, which can be measured by quantitative figures, such as the numbers of mobile students and scholars, international partner HEIs, transnational programmes, English or bilingual courses, and international publications etc. (p. 178)

What has motivated and sustained the prevalence of quantifiable measures of progress is the "leaping forward in development" (Ngok \& Guo, 2008) mindset which undergirds many policies, projects, schemes, and plans in the country's higher education as well as other domains of practice. There is nothing wrong with an eagerness to succeed; however, the haste with which progress is achieved may have a lasting influence on the beliefs, values, and philosophy that shape the practices in education and beyond.

The "outsourced" training for academic staff in mainland Chinese universities presents a case where the value of the personnel's overseas experience was tapped to improve productivity and efficiency that transform into assets for local benefits. In the short run, it may have proven to be an effective shortcut to progress as manifested in the rising figures and curves (Ministry of Education "China has established the world's largest higher education system", 2020). In the long run, however, a lopsided reliance on "outsourcing" at the expense of due attention and efforts to improve local teaching and learning practices may have detrimental consequences.

It is heartening to note that policymakers have become aware of the possible adverse effects and have taken measures to reverse this trend. For example, a breakthrough decision has recently been made in faculty evaluation policies that intend to reduce preoccupation with educational background, titles, positions, and quantity of publications (Ministry of Education "Work plan for the fifth round of discipline evaluation", 2020). Nevertheless, how these unfolding policies translate into local practices that can induce meaningful changes remains to be seen.

Overall, critical reflections on the "fast-lane" approach bring us back to the fundamental question: What does "internationalisation" mean in the internationalisation of higher education? The simple and reserved answer seems to be: it means different things to different parties in different systems. For some, it is a means of survival (Chen \& Lo, 2013), while for others, a pursuit of excellence. From the perspective of the system, becoming international is about being open to the world, with easy access to the world's store of information and knowledge. Meanwhile, it also means an embracing attitude towards individuals, learners and teachers alike, with more respect for individual merits and diversity in backgrounds and experiences. Above all, the significance of becoming international transcends the value of the statistics and rankings. It is a potential for systems and individuals to connect, grow, and free themselves of the constraints of a parochial view.

\section{The tension between domestic and foreign talent management practices in the "massification" of overseas education}

With increasing communication and mobility, new trends have emerged in systems that have been investing tremendous efforts to become more international. One consequence is the merging of boundaries between the foreign and the domestic, as evidenced most readily by the diverse choices of goods in a globalised market. On the one hand, considerable efforts have been made to accommodate the "golden guests" (Marini \& Xu, 2021) by assimilating and integrating foreign faculty into the local community. In some institutions, such efforts have helped melt the distinction between the foreign and the nonforeign 
(Chen, 2021). On the other hand, however, the preferential hiring practices in the academic job market seem to have been working in the opposite direction. That is, they tend to draw a wedge between the domestic and the foreign PhDs by clearly separating the two groups based on a set of stereotypical assumptions, thus deepening the playful distinction drawn between "hăigu $\vec{\imath}$ " ("sea turtles") versus "tǔbiè " ("land turtles" or "ground beetles") (Kan, 2004).

Why would the domestic PhDs, including those cultivated in the country's top institutions, see themselves struggling somewhat desperately against the challenges of competing with their foreign-educated peers? One apparent reason is the growing accessibility of international learning experience to the masses. Only decades ago, going abroad to pursue further study was a distant topic to most common households in China. Today, however, many Chinese families can afford their children's overseas experience and would happily make that investment. Among the hundreds of thousands of Chinese students travelling and/or studying abroad every year, some are striving to compete with native students in the host country for resources and opportunities; some are busy gaining cultural and social network capital in preparation for their planned career back home; while others are doing little more than having a good time on their academic tour abroad. All are gaining overseas experience of some kind, yet the employers have grown increasingly aware of the difference. With China's remarkable economic growth, it has taken less than three decades for "liúxuê" ("studying overseas") to change from a trendy catchword to a household vocabulary, as the meaning of "overseas" credentials (Waters, 2009) began to matter. It is thus reasonable to predict that the country would soon embrace an era of the "massification" of overseas education, as has already been achieved in some highly-developed regions.

What this emerging "massification" of overseas education possibly brings is a growing tension between domestic and foreign talent management policies and practices. While staffing the competitive HEIs with the internationalised academics would help accelerate the institution's growth and contribute to the national ambition of achieving world-class distinction, it would nonetheless limit the options for domestically trained graduates. Paradoxically, these early-career academics need an academically sound environment to develop research skills and make up for the lack of international experience and other limitations likely arising from their apprenticeship in the domestic programme (Shen \& Chen, 2018).

As to where domestically cultivated talents are going, a future was envisioned by Zhu Yongxin, deputy secretary-general of the 13th National Committee of the Chinese People's Political Consultative Conference:

In the future, education in China will become more international and more open to the outside world. In particular, with the development of the Internet and information technology, educational exchanges and cooperation between countries will become more convenient and extensive. Therefore, we need to be more open-minded and learn from advanced international education models and concepts, and we need to further strengthen our cooperation with international educational institutions with innovative features to further cultivate international talents with Chinese sentiments and a global vision. (Ministry of Education, 2018)

In contrast to the neo-nationalist sentiment (Fischer, 2021) expressed in the ambition to cultivate "international talents with Chinese sentiments and a global vision", there seems to be a lack of confidence to fulfil the ambition felt on all sides: the employers, the general public, and even the students themselves. A better understanding of this situation will enable us to reconsider that innocent question arising from the domestic 
PhD students' grumbling responses: "Why should a 'foreigner' be better than me?" For a well-constructed blueprint to materialise, it ought to be associated with concrete measures to promote teaching practices and actual growth in learning outcomes. On the whole, any endeavour towards internationalisation and world-class distinction cannot be considered successful and sustaining, if, at the end of the day, only those sitting at the top were the "winners" of the policy (Ngok \& Guo, 2008, p. 556). Only with sincere efforts to eliminate the "inner constraints with respect to social equity and human fulfilment" (Zha, 2011, p. 766) would domestic students be able to compete equally and competently with their overseas-educated peers.

\section{Conclusions}

This qualitative inquiry investigated two questions: Whether and to what extent did an overseas background preference exist in academic hiring practices among Chinese university employers, as evidenced in the university's recruiting advertisements? And how did domestic PhD students respond to this situation? Overall, the results revealed a prevalence of university employers' preferences of overseas-trained candidates, with their institutional background and potential academic productivity being prioritised concerns in the hiring decision. For home-grown doctoral students, lacking the experience of receiving training in a foreign institution may cripple one's academic career opportunities. The domestic $\mathrm{PhDs}$ tended to yield to the pressure of competing with their overseas-educated peers by making compromises and adaptations.

In general, the study has offered implications that could be meaningful beyond the Chinese context. The preliminary findings help refine previous findings on the overseas background advantage in the academic labour market in expanding higher education systems. Reflecting on the study findings, there is a pressing need to reassess the recruitment policies. While focusing on hiring talents who can readily contribute to enhancing the university's international profile and academic performance, employers also need to take the responsibility to provide domestically trained graduates with choices and opportunities to develop and realise their potentials. Efforts are needed to restore balance to the disturbed system of talent management for a healthy academic culture that would sustain the growth of higher education in the local context.

Given the sheer number of Chinese HEIs, the cases examined in the current study are not claimed to represent nationwide practice, nor any broader scope of recruitment practices in the Chinese higher education labour market. Nonetheless, they could be considered with some validity for an enquiry seeking to understand faculty recruitment policy among Chinese HEIs. Studies of a larger scale and more enhanced datasets along this line can expect to achieve a more comprehensive picture of the preferential practices under discussion. Empirical evidence is needed to reveal the criteria considered important by HEIs at different levels and how they may affect actual recruitment practices. The heightened distinction between domestic and overseas talents in the popularisation of overseas education makes an interesting topic where further research can be conducted to explore the ongoing changes in China and other higher education systems. Further reflections should also be made on how hiring policies can be improved to be more compatible with equality of opportunity. 
Acknowledgements The study is partially funded by the Ministry of Education of the People's Republic of China (grant no. 21YJC740005). The author is deeply grateful for the feedback and encouragement from the journal editor and anonymous reviewers. She would also like to thank the informants for their time and trust in generously sharing their thoughts and experiences.

\section{Declarations}

Competing interests The author declares no competing interests.

\section{References}

Anthony, L. (2015). AntConc. Waseda University

Bao, W., Du, Q., \& Ma, J. (2020). To be or not to be an academic: The academic professional intentions of PhD students and influencing factors. Chinese Education \& Society, 53(3), 97-114

Brødsgaard, K. E. (2002). Institutional reform and the Bianzhi System in China. The China Quarterly, 170, 361-386

Burgan, M. (2006). What ever happened to the faculty?: Drift and decision in higher education. JHU Press

Burris, V. (2004). The academic caste system: Prestige hierarchies in PhD exchange networks. American Sociological Review, 69(2), 239-264

Cai, Y. (2014). Institutionalisation of internationalisation of higher education in China. Frontiers of Education in China, 9(2), 175-181

Cao, C. (2008). China's brain drain at the high end: why government policies have failed to attract first-rate academics to return. Asian Population Studies, 4(3), 331-345

Chen, S. (2021). Nonforeign foreign academics in Hong Kong: Realities and strategies. In F. Huang., \& R. A. Welch (Eds.), International faculty in Asia: The changing academy. The changing academic profession in international comparative perspective, Vol. 21 (pp. 33-44). Springer

Chen, D., \& Lo, W. (2013). Internationalisation or commodification? A case study of internationalisation practices in Taiwan's higher education. Asia Pacific Education Review, 14(1), 33-41

Chiang, L. C. (2021). Academic profession in Taiwan: Whose doctorate graduates hold a stronger network among academics? In A. Y. C. Hou, T. Chiang., \& S. J. Chan (Eds.), Higher education in Asia: Quality, excellence and governance (pp. 215-232). Springer

Clark, R. L., \& Ma, J. (Eds.). (2005). Recruitment, retention, and retirement in higher education: Building and managing the faculty of the future. Edward Elgar Publishing

Crothall, J., Callan, V., \& Härtel, C. E. (1997). Recruitment and selection of academic staff: perceptions of department heads and job applicants. Journal of Higher Education Policy and Management, 19(2), 99-110

Fan, W., Wang, G., \& Chen, X. (2017). Permanent teacher qualifications: "Surviving within the Iron Rice Bowl”. In F. Pawan, W. Fan., \& P. Miao (Eds.), Teacher training and professional development of Chinese English language teachers: Changing from fish to dragon (pp. 41-50). Taylor \& Francis

Fischer, K. (2021). Nationalism revived: China's universities under President Xi. In J. A. Douglass (Ed.), Neo-nationalism and universities: Populists, autocrats, and the future of higher education (pp. 160201). Johns Hopkins University Press

Gaskell, J., Eichler, M., Pan, J., Xu, J., \& Zhang, X. (2004). The participation of women faculty in Chinese universities: Paradoxes of globalisation. Gender and Education, 16(4), 511-529

Gu, J., Levin, J. S., \& Luo, Y. (2018). Reproducing "academic successors" or cultivating "versatile experts": Influences of doctoral training on career expectations of Chinese PhD students. Higher Education, 76(3), 427-447

Ha, W., Yi, J., \& Zhang, J. (2016). Brain drain, brain gain, and economic growth in China. China Economic Review, 38, 322-337

Hao, J., \& Welch, A. (2012). A tale of sea turtles: Job-seeking experiences of hai gui (high-skilled returnees) in China. Higher Education Policy, 25(2), 243-260

Headworth, S., \& Freese, J. (2016). Credential privilege or cumulative advantage? Prestige, productivity, and placement in the academic sociology job market. Social Forces, 94(3), 1257-1282

Hearn, J. C., McLendon, M. K., \& Lacy, T. A. (2013). State-funded "Eminent Scholars" programs: University faculty recruitment as an emerging policy instrument. The Journal of Higher Education, 84(5), 601-639 
Hirsch, J. E. (2005). An index to quantify an individual's scientific research output. Proceedings of the National Academy of Sciences, 102(46), 16569-16572

Jiang, J., \& Ke, G. (2021). China's move to mass higher education since 1998: Analysis of higher education expansion policies. Higher Education Quarterly. https://doi.org/10.1111/hequ.12313

Jiang, J., Mok, K. H., \& Shen, W. (2020). Riding over the national and global disequilibria: international learning and academic career development of Chinese Ph. D. returnees. Higher Education Policy, 33, $531-554$

Jung, J. (2018). Domestic and overseas doctorates and their academic entry-level jobs in South Korea. Asian Education and Development Studies, 7(2), 205-222

Kan, D. (2004). "Sea turtles" and "ground beetles" [land turtles] should shake hands. Chinese Education \& Society, 37(2), 12-14

Li, F., Ding, J., \& Shen, W. (2019). Back on track: Factors influencing Chinese returnee scholar performance in the reintegration process. Science and Public Policy, 46(2), 184-197

Li, F., Miao, Y., \& Yang, C. (2015). How do alumni faculty behave in research collaboration? An analysis of Chang Jiang Scholars in China. Research Policy, 44(2), 438-450

Li, J., \& Xue, E. (2021). Returnee faculty responses to internationalising "academic ecology" for creating world-class universities in China's elite universities. Higher Education, 81, 1063-1078

Li, M., \& Pu, H. (2017). Recruiting returnees: A study of Chinese university presidents' perceptions of foreign-educated returnees at Chinese universities. Journal of Media Critiques, 11, 21-32

Liu, Y. (2015). Geographical stratification and the role of the state in access to higher education in contemporary China. International Journal of Educational Development, 44, 108-117

Lu, J. (2017). Ideological and political education in China's higher education. East Asian Policy, 9(2), 78-91

Marini, G. (2018). Higher education staff and Brexit: Is the UK losing the youngest and brightest from other EU countries? Tertiary Education and Management, 24(4), 409-421

Marini, G., \& Xu, X. (2021). "The golden guests”? International faculty in mainland Chinese universities. Society for Research into Higher Education (SRHE) Research Report. Retrieved from https://srhe.ac. uk/wp-content/uploads/2021/10/SRHE-Research-Report_Marini_Xu_Oct-2021_Final.pdf. Accessed 19 Oct 2021

Marini, G., \& Yang, L. (2021). Globally bred Chinese talents returning home: An analysis of a reverse brain-drain flagship policy. Science and Public Policy, scab021. https://doi.org/10.1093/scipol/scab021

Melin, G. (2004). Postdoc abroad: Inherited scientific contacts or establishment of new networks? Research Evaluation, 13(2), 95-102

Ministry of Education of the People's Republic of China (2015). 2015 nian quanguo gaodeng xuexiao mingdan [List of Chinese higher education institutions 2015]. Retrieved from http://www.moe.gov.cn/srcsi te/A03/moe_634/201505/t20150521_189479.html. Accessed 15 Oct 2017

Ministry of Education of the People's Republic of China (2018). Quanguo zhengxie weiyuan minjin zhongyang fuzhuxi zhuyongxin: jinyibu kuoda zhongguo wenhua yingxiangli [Zhu Yongxin, member of the National Committee of the Chinese People's Political Consultative Conference and vice chairman of the Democratic Progressive Central Committee: Further expand the influence of Chinese culture]. Retrieved from http://www.moe.gov.cn/jyb_xwfb/xw_zt/moe_357/jyzt_2018n/2018_zt07/zt1807_ dbwy/201803/t20180320_330600.html. Accessed 9 July 2021

Ministry of Education of the People's Republic of China (2020). Woguo yi jiancheng shijie guimo zuida gaodeng jiaоyu tixi [China has established the world's largest higher education system]. Retrieved from http://www.moe.gov.cn/fbh/live/2020/52717/mtbd/202012/t20201203_503281.html. Accessed 9 July 2021

Ministry of Education of the People's Republic of China (2020). Jiaoyubu caizhengbu guojia fazhan gaigewei guanyu gongbu shijie yiliu daxue he yiliu xueke jianshe gaoxiao ji jianshe xueke mingdan de tongzhi [Notice issued by the Ministry of Education, the Ministry of Finance and the National Development and Reform Commission on the announcement of the list of world-class universities and firstclass disciplines]. Retrieved from http://www.moe.gov.cn/srcsite/A22/moe_843/201709/t20170921_ 314942.html. Accessed 25 June 2021

Ministry of Education of the People's Republic of China (2020). Di wu lun xueke pinggu gongzuo fangan [Work plan for the fifth round of discipline evaluation]. Retrieved from http://www.moe.gov.cn/jyb_ xwfb/moe_1946/fj_2020/202011/t20201102_497819.html. Accessed 9 July 2021

Mok, K. H., \& Han, X. (2016). From ‘brain drain’to 'brain bridging': Transnational higher education development and graduate employment in China. Journal of Higher Education Policy and Management, 38(3), 369-389

Ngok, K., \& Guo, W. (2008). The quest for world class universities in China: Critical reflections. Policy Futures in Education, 6(5), 545-557 
Oprisko, R., Dobbs, K., \& DiGrazia, J. (2013). Pushing up ivies: Institutional prestige and the academic caste system. Georgetown Public Policy Review, published online 31 August. Retrieved from https:// papers.ssrn.com/sol3/papers.cfm?abstract_id=2317992. Accessed 19 July 2021

Qin, X. (2007). Zhongwai gaoxiao shizi guanli bijiao yanjiu [A comparative study of teaching faculty management in Chinese and foreign universities]. Hunan Education Press

Roemer, R. E., \& Schnitz, J. E. (1982). Academic employment as day labor: The dual labor market in higher education. The Journal of Higher Education, 53(5), 514-531

Shen, W., \& Chen, H. (2018). Chinese doctoral education quality and employment in the context of education expansion. Chinese Education \& Society, 51(3), 155-157

Song, J. (2018). Creating world-class universities in China: Strategies and impacts at a renowned research university. Higher Education, 75(4), 729-742

State Council of the People's Republic of China (2011). Guiding opinions of the State Council on the reform of classification and promotion of public service units [zhonggong zhongyang guowuyuan guanyu fenlei tuijin shiye danwei gaige de zhidao yijian], 23 March. Retrieved from http://www.gov.cn/jrzg/201204/16/content_2114526.htm. Accessed 11 Oct 2018

Tharenou, P., \& Seet, P. S. (2014). China's reverse brain drain: Regaining and retaining talent. International Studies of Management \& Organization, 44(2), 55-74

Wang, X., Wang, C., \& Wang, J. (2019). Towards the contributing factors for stress confronting Chinese PhD students. International Journal of Qualitative Studies on Health and Well-being, 14(1), 1598722

Waters, J. L. (2009). Transnational geographies of academic distinction: the role of social capital in the recognition and evaluation of "overseas" credentials. Globalisation, Societies and Education, 7(2), 113-129

Wong, C. (2009). Rebuilding government for the 21st century: Can China incrementally reform the public section? The China Quarterly, 200, 929-952

Xiong, T. (2012). Discourse and marketisation of higher education in China: The genre of advertisements for academic posts. Discourse \& Society, 23(3), 318-337

Yang, R. (2012). Up and coming? Doctoral education in China. Australian Universities' Review, 54(1), 64-71

Zha, Q. (2011). China's move to mass higher education in a comparative perspective. Compare, 41(6), 751-768

Zhang, J., Wang, R., \& Lu, C. (2019). A quantitative analysis of Hukou reform in Chinese cities: 20002016. Growth and Change, 50(1), 201-221

Zheng, G., Shen, W., \& Cai, Y. (2018). Institutional logics of Chinese doctoral education system. Higher Education, 76(5), 753-770

Zweig, D. (2006). Competing for talent: China's strategies to reverse the brain drain. International Labour Review, 145(1-2), 65-90

Zweig, D., Chen, C., \& Rosen, S. (2004). Globalisation and transnational human capital: Overseas and returnee scholars to China. The China Quarterly, 179, 735-757

Publisher's Note Springer Nature remains neutral with regard to jurisdictional claims in published maps and institutional affiliations. 